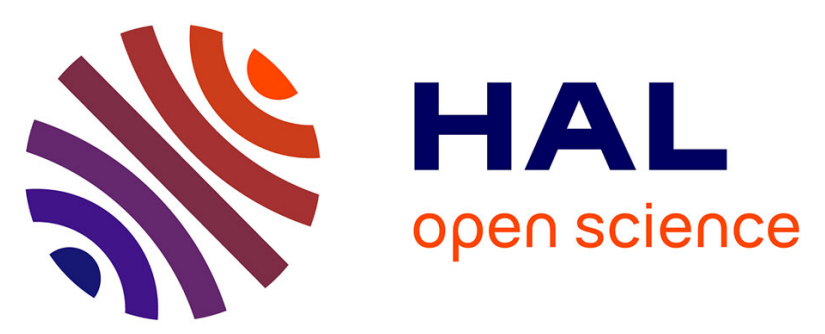

\title{
The Aircraft Noise Simulation Working Group (ANSWr) -Tool Benchmark and Reference Aircraft Results
}

\author{
Lothar Bertsch, Ian A. Clark, Russell H. Thomas, Laurent Sanders, Ingrid
}

Legriffon

\section{- To cite this version:}

Lothar Bertsch, Ian A. Clark, Russell H. Thomas, Laurent Sanders, Ingrid Legriffon. The Aircraft Noise Simulation Working Group (ANSWr) -Tool Benchmark and Reference Aircraft Results. 25th AIAA/CEAS Aeroacoustics Conference, May 2019, DELFT, Netherlands. hal-02196662

\section{HAL Id: hal-02196662 \\ https://hal.science/hal-02196662}

Submitted on 29 Jul 2019

HAL is a multi-disciplinary open access archive for the deposit and dissemination of scientific research documents, whether they are published or not. The documents may come from teaching and research institutions in France or abroad, or from public or private research centers.
L'archive ouverte pluridisciplinaire HAL, est destinée au dépôt et à la diffusion de documents scientifiques de niveau recherche, publiés ou non, émanant des établissements d'enseignement et de recherche français ou étrangers, des laboratoires publics ou privés. 


\title{
The Aircraft Noise Simulation Working Group (ANSWr) - Tool Benchmark and Reference Aircraft Results
}

\author{
Lothar Bertsch; \\ DLR, Institute of Aerodynamics and Flow Technology, Göttingen \\ Ian A. Clark $\dagger$ Russell H. Thomas, \\ NASA Langley Research Center, Aeroacoustics Branch, Hampton \\ Laurent Sanders, and Ingrid LeGriffon ${ }^{\text {II }}$ \\ ONERA, Department of Aeroacoustics, Chatillon Cedex
}

\begin{abstract}
The Aircraft Noise Working Group (ANSWr) was established by DLR, ONERA, and NASA to compare simulation tools, establish guidelines for noise prediction, and to assess uncertainties associated with the simulation. To accomplish these goals, a benchmark problem was initiated by the group. The setup is documented and initial results for the reference aircraft are discussed. The reference aircraft is a conventional tube-andwing configuration with the engines installed under the wings. The aircraft noise simulations are performed for departure and approach conditions, and the results obtained with three different system noise prediction tools are compared. At the aircraft level, the overall agreement is good between the three predictions. Peak noise levels agree within 3-4 dB. Fan and jet component predictions are generally very similar although there can be differences of up to $7 \mathrm{~dB}$ in some fan tone levels. The prediction of airframe components shows the most disagreement between the three methods with some differences of $6 \mathrm{~dB}$ for the major components and greater differences at high frequencies. There can also be differences in the frequency of the peak level and in the rank order of the airframe components. At the total airframe noise level, the differences are reduced to no more than 3-4 dB. While there is general agreement in shape characteristics of predicted ground noise isocontours, the differences between the three methods can result in more significant disagreement in the sizes of the isocontours.
\end{abstract}

\section{Nomenclature}

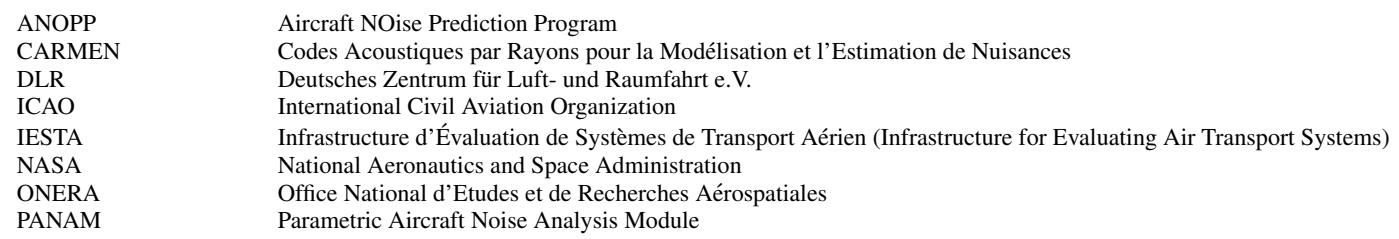

$\begin{array}{lll}\text { Metrics } & & \\ \text { Variable } & \begin{array}{l}\text { Name } \\ \text { effective perceived noise level }\end{array} & \text { Unit } \\ \text { EPNL } & \text { sound exposure level } & \text { EPNdB } \\ \text { SEL } & \text { sound pressure level } & \text { dBA } \\ \text { SPL } & \text { 1/3-oct. band overall SPL } & \text { dB } \\ \text { SPL }_{1 / 3} & \text { A-weighted SPL } & \text { dB } \\ \text { SPL(A) } & \text { 1/3-oct. band SPL(A) } & \text { dBA } \\ \text { SPL }_{1 / 3}(\mathrm{~A}) & \text { tone corrected perceived noise level } & \text { dBA } \\ \text { PNLT } & & \text { PNdB }\end{array}$

\footnotetext{
*DLR, Institute of Aerodynamics and Flow Technology, Bunsenstr. 10, 37073 Göttingen, lothar.bertsch@dlr.de

${ }^{\dagger}$ NASA Langley Research Center, Aeroacoustics Branch, 2 N. Dryden St., MS 461, Hampton, VA 23681. AIAA Member

¥NASA Langley Research Center, Aeroacoustics Branch, 2 N. Dryden St., MS 461, Hampton, VA 23681. AIAA Associate Fellow

$\S$ ONERA, Department of Aeroacoustics, 29 avenue de la Division Leclerc, FR-92322 Chatillon Cedex

IIONERA, Department of Aeroacoustics, 29 avenue de la Division Leclerc, FR-92322 Chatillon Cedex

Copyright $@ 2019$ by the authors. Published by the American Institute of Aeronautics and Astronautics, Inc., with permission.
} 


$\begin{array}{ll}\text { Terminology } & \\ \text { HeNAP } & \text { Helical Noise Abatement Procedure } \\ \text { ILS } & \text { Instrument Landing System } \\ \text { PAA } & \text { Propulsion Airframe Aeroacoustic integration or interaction effects } \\ \Phi & \text { azimuthal / lateral directivity, }+90^{\circ} \text { equals to starboard } \\ \Theta & \text { polar / longitudinal directivity, } 0^{\circ} \text { equals flight direction }\end{array}$

$\begin{array}{ll}\text { Plot legend } & \\ \text { airf } & \text { sum of t.e., l.e. and gear } \\ \text { t.e. } & \text { sum of all trailing edge noise (overall vehicle) } \\ \text { l.e. } & \text { sum of all leading edge noise (overall vehicle) } \\ \mathrm{mg} & \text { sum of main landing gear noise (overall vehicle) } \\ \mathrm{ng} & \text { sum of nose landing gear noise (overall vehicle) } \\ \mathrm{eng} & \text { sum of fan and jet } \\ \text { fan } & \text { sum of inlet and exhaust fan noise (all engines) } \\ \text { fan bb } & \text { fan: only broadband noise (all engines) } \\ \text { fan t } & \text { fan: only tonal noise (all engines) } \\ \text { jet } & \text { sum of jet noise (all engines) }\end{array}$

\section{Introduction}

Community annoyance caused by aircraft noise continues to be a major issue impacting the growth of the global air transport system. The constant increase in air traffic, and at the same time, increasing population density around major airports and along common air traffic routes, will negatively affect this situation in the near future. In general, there are four approaches in order to mitigate the impact of aircraft noise, as specified by $\mathrm{ICAO}^{1}$. Their balanced approach is comprised of (1) modifications at the source, (2) land-use planning, (3) noise abatement operational procedures, and (4) operational restrictions, e.g., nighttime curfew.

In order to assess the impact of these approaches on the overall aircraft noise, advanced simulation capabilities become essential. The aircraft noise generation, the sum of its components, and the sound propagation to the observer on the ground have to be adequately modeled along the entire simulated flight path of the aircraft. Furthermore, to assess the ICAO measures, all the modifications have to be accounted for at the same time with consideration for implications on other disciplines. Therefore, all relevant noise-emitting components on board have to be accounted for in order to get a realistic approximation for the overall aircraft noise. Furthermore, the simulation has to be able to reflect the complex interaction and interdependencies among these components. Each of these component contributions is highly dependent on (1) the individual design of aircraft and engine and (2) the varying operational conditions along the simulated flight. Consequently, all relevant noise contributions have to be accounted for in a parametric way. Only then, will modifications as proposed by ICAO impact the noise source ranking along a realistic flight procedure and ultimately influence the total aircraft noise as perceived on the ground. In conclusion, adequate simulation tools are required and the three organizations DLR, NASA, and ONERA have developed their own tool, respectively.

In October 2012, DLR initiated the Aircraft Noise Simulation Working Group (ANSWr) which gathers together the three research centers to establish a better common understanding of aircraft noise simulation. It is planned to establish some guidelines on the application of these tools and on the interpretation of the results, i.e., application limitations and uncertainty assessment. Consequently, a direct tool-to-tool comparison between the three codes PANAM, ANOPP and CARMEN has been underway. Such a comparison does help to assess the quality and reliability of the predicted levels by each tool. In addition, lessons learned and knowledge on validation of predicted results with experiments or higher fidelity numerical methods is discussed within ANSWr. 


\section{Aircraft Noise Simulation Tools}

Simulation tools for prediction of overall aircraft system noise by the three organizations are briefly introduced here. Certain noise sources have been selected for this benchmark test. The underyling noise source models as used within PANAM, ANOPP, and CARMEN are described in Section IV. More information about the simulation of noise shielding is provided in an accompanying paper ${ }^{2}$.

\section{A. PANAM by DLR}

DLR activities in the field of noise source modeling can be found in the literature from the year $2000 \mathrm{on}^{3-5}$. Dedicated models to describe certain noise contributors on board have been further developed, and new models for other noise sources and interaction effects are under investigation since then. From 2008 on, the DLR noise source models have been implemented into an aircraft system noise simulation process ${ }^{6}$. Since then, the corresponding simulation tool PANAM has been further improved and updated, e.g., to incorporate noise shielding effects or acoustic lining material.

\section{B. ANOPP by NASA}

NASA has been continually developing an aircraft system noise prediction capability since the 1970s beginning with $\mathrm{ANOPP}^{7}$. For more than ten years, both the noise prediction methods of ANOPP and the second generation framework, ANOPP $2^{8}$, continue to be developed specifically for the challenges of higher fidelity predictions and the needs for future, advanced low noise aircraft configurations. An added motivation is to develop the expanded capability to predict the noise from future technology and revolutionary low noise aircraft configurations ${ }^{9,10}$ for which PAA effects are critical.

\section{CARMEN by ONERA}

Since 2008, ONERA has been developing the IESTA platform to design and model innovative air transport systems ${ }^{11,12}$. Several models (ground planning, aircraft, engine, acoustics and chemical dispersion) are implemented in the IESTA platform to account for the physics of the environmental impact of the air traffic surrounding airports, including noise and chemical emissions. The noise prediction tool CARMEN implemented in IESTA is composed of three modules: the noise sources, the installation effects and the atmospheric propagation ${ }^{13}$.

\section{ANSWr}

\section{A. Motivation}

The focus of the joint activities in ANSWr is the simulation of the aircraft noise immission, or total aircraft noise levels as perceived at selected ground-based observers. Thereby, the noise levels are comprised of all relevant components, i.e., the sum of all major individual noise sources. The total aicraft noise as the sum of individual noise sources when received on the ground is referred to as aircraft system noise ${ }^{14}$.

Aircraft system noise can only be predicted if the aircraft is modeled along a simulated flight; the assessment of individual and representative operating conditions does not suffice anymore. This is in direct contrast with other known research activities that focus solely on the noise emission of a selected individual noise source under a fixed operating condition. Consequently, a system noise assessment can only be realized if all noise sources can be accounted for as they become relevant along a simulated flight. The required input data complexity for the system noise prediction has to be sufficiently low while still capturing the relevant physics. Consequently, only simple and relatively fast prediction methodologies can be applied.

Validation possibilites for aircraft system noise simulation are very limited and usually not directly available. Whereas, individual noise source models could directly be compared to experimental data from wind tunnel measurements or high-fidelity simulation for predefined and fixed operating conditions; this is extremely complicated if not impossible for the overall system. Neither wind-tunnel measurements nor high-fidelity simulations are able to handle 
an overall aircraft, including all the main noise sources. Moreover, the overall aircraft would have to be assessed under a multitude of varying operating conditions. In order to assess the overall vehicle, the complex interaction of individual noise sources, experimental or numerical data for the overall vehicle under all relevant operating conditions are required. Experimental data are already very limited, and the high fidelity simulation capabilites are far from handling an overall aircraft under realistic and varying operating conditions. Furthermore, even if an extensive amount of experimental data were available, one still would have to be able to separate the impact of each individual source. The noise signal as measured on the ground would, therefore have to be separated into individual noise components, which is very difficult - despite the advancing techniques of beamforming - unless a strong noise source dominates the overall noise ${ }^{15}$.

At this point, a reasonable approach to assess aircraft system noise is to use simulations based on semiempirical noise models, including installation effects on aircraft and acoustic propagation through the atmosphere at a moderate computational cost. This is the approach implemented in the system noise assessment tools as presented in II. A to II. C within this paper. These tools predict the noise impact on the ground. They produce several noise descriptors such as noise footprints or contour areas and, more specifically, noise emission spectra and time-histories of ground noise levels. These numerical noise predictions are rarely validated against measurements. On one hand, the access to both flight data and noise measurements is restricted as previously mentioned, and, if available, noise measurements are, in this case, often limited to a few microphones. This has direct consequences on the prediction validation of the key metric of ground noise footprints or contours. Measurement of these contours for existing aircraft is challenging, at best. The shape of these predicted contours can change dramatically with the selection of a model for ground noise reflection or by the selection of a characteristic ground property that is assumed constant over the simulation area. Selecting different ground reflection models or ground properties can easily change the calculated footprint area by $20 \%$ or more.

In addition to the generally limited amount of flight acoustic test information that can be used for noise prediction validation, an increasing emphasis is placed on the development of future aircraft concepts with novel technology and unconventional aircraft configurations. For these concepts, by definition, the full-scale realized aircraft does not exist, and validation of system noise prediction results with flight data is not likely in the near future.

Given these challenges, a direct comparison of predictions from comparable system noise prediction tools provides one logical and valuable method of assessment and verification of tool prediction capabilities and processes. Ultimately, this tool comparison will also help to establish a common understanding of the many aspects of the aircraft system noise prediction process. This will lead to some generally proposed guidelines for the application of these tools and for the interpretation of the results including qualifications and uncertainty quantification. The comparison of the different simulation results is understood as an helpful step toward a quality assessment.

\section{B. Goals}

The goals of the ANSWr collaboration are stated as:

- to classify existing aircraft system noise prediction tools and include a description of the general differences in approaches,

- to develop guidelines for the interpretation of results,

- to share general experience and increase the knowledge base in the area of aircraft system noise prediction,

- to identify uncertainties associated with particular simulation capabilities at each partner organization,

- to identify some of the challenges and modeling improvements needed in the future for applicability to novel technologies and unconventional aircraft designs,

- to directly compare prediction tool results for one existing aircraft flight test with an unconventional engine installation over the wing.

To achieve these goals, a benchmark for the code-to-code comparison is presented in this paper by the three research institutions, i.e., a comparison of the PANAM, ANOPP, and CARMEN prediction results. Two major test cases are 
defined, i.e., (1) a fully numerical assessment and (2) a comparison with experimental data. Three different aircraft are available for this benchmark, two virtual concepts and one existing aircraft with flyover noise measurements.

At this point, results obtained for the two virtual aircraft configurations are available, while a detailed comparison of the numerical and experimental data is still under way and those results are not yet available. This paper describes the benchmark setup including a comparison of the numerical results obtained with each code for a conventional tubeand-wing aircraft, referred to as the reference vehicle, V-R. Benchmark results for a low-noise vehicle, referred to as $\mathrm{V}-2$, are presented in an accompanying paper $^{2}$.

\section{Benchmark setup}

Two major test cases are defined for (1) a fully numerical assessment and (2) an assessment of numerical results versus experimental data. These are referred to as Technical Challenge (TC) 1 and 2. The TC-1 is furthermore subdivided into two different assessments: (a) assessment under constant operating conditions and (b) assessment along typical flight trajectories. Each partner applies its in-house simulation tools to simulate these test cases. Overall, 19 simulation runs are defined for the benchmark test, see Table 2. Several assumptions were made to simplify the assessment and to enable a comparison. Thus, the effects of engine lining and ground attenuation were ignored. Furthermore, the assessment was limited to the following noise sources:

1. airframe broadband noise (abbreviation: airf); comprised of:

(a) clean / trailing edge noise and flap side edge noise (abbreviation: t.e.)

(b) leading edge noise (abbreviation: 1.e.)

(c) main landing gear noise (abbreviation: $\mathrm{mg}$ )

(d) nose landing gear noise (abbreviation: ng)

2. engine tonal and broadband noise (abbreviation: eng); comprised of:

(a) fan broadband noise (abbreviation: fan bb)

(b) fan tonal noise (abbreviation: fan t)

(c) jet noise (abbreviation: jet)

Each source contribution as specified above is the sum of all equivalent elements, e.g., all trailing edge elements on board of the vehicle are summed up to give the t.e. contribution. For all simulations of this benchmark, the overall vehicle is approximated as the sum of these airframe and engine noise sources. Table 1 lists the methods within the tree prediction tools that are used for each noise contribution, including available references. For certain simulation runs, additional effects such as structural shielding are accounted for, if required.

\begin{tabular}{|c|c|c|c|}
\hline & PANAM & ANOPP & CARMEN \\
\hline \multicolumn{4}{|c|}{ airframe noise models (airf) } \\
\hline t.e. & DLR Airframe $e^{4-6,16-18}$ & $\begin{array}{l}\text { Boeing Airframe }{ }^{19} \text { : Flap, Fink }{ }^{20}: \text { Trailing } \\
\text { Edge }\end{array}$ & DLR Airframe $^{4,5,16}$ : Flap, Fink ${ }^{20}$ : Trailing Edge \\
\hline $\mathrm{mg}$ & DLR Airframe ${ }^{4-6,16}$ & Boeing Airframe $e^{22}$ & DLR Airframe ${ }^{4,5,16}$ \\
\hline ng & DLR Airframe $\mathrm{e}^{4-6,16}$ & Boeing Airframe ${ }^{22}$ & DLR Airframe $e^{4,5,16}$ \\
\hline \multicolumn{4}{|c|}{ engine noise models (eng) } \\
\hline fan $t$ & modified Heidmann $^{23}$ & Heidmann Fan $^{23}$, GE Large Fan Option ${ }^{24}$ & modified Heidmann Fan $^{23}$ and Kontos ${ }^{24}$ \\
\hline jet & modified Stone $\mathrm{e}^{25}$ & Stone $2^{26}$ & modified Stone ${ }^{25}$ \\
\hline \multicolumn{4}{|c|}{ sound propagation effects } \\
\hline- & ISO $9613^{27}$ & ISO $9613^{27}$ & ISO $9613^{27}$ \\
\hline
\end{tabular}

Table 1: Summary of simulation models used within PANAM, ANOPP, and CARMEN. 


\section{A. Input data}

The corresponding input data for all 19 simulation runs were provided by DLR as specified in Table 2, Appendix. All aircraft simulation models were generated with the aircraft design synthesis code PrADO of TU Braunschweig ${ }^{28}$. The engine performance calculation within PrADO was replaced by high-quality engine data from DLR ${ }^{29}$. Furthermore, the detail design of the engine, e.g., rotor-stator spacing, was provided as external input since it is not a result of PrADO. The input data for each acoustic simulation is comprised of information on the following:

- conceptual aircraft design; see Refs. ${ }^{6,28,30}$

- flight procedure; see Refs. ${ }^{6,28,31}$

- high-quality engine design \& performance; see Ref. ${ }^{29}$

Additional experimental data was provided for the final comparison as scheduled within TC-2. This experimental data was recorded during a dedicated flyover campaign as described in Ref. ${ }^{31}$.

The aircraft models for TC-1 were selected from a DLR low-noise design study in 2013, see Ref. ${ }^{6}$. Approximately 500 vehicle variants have been the subject of a detailed analysis of performance parameters versus system noise at selected observer locations. The analysis of each vehicle variant included a full simulation and convergence of the

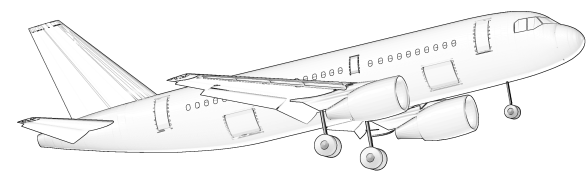

(a) V-R

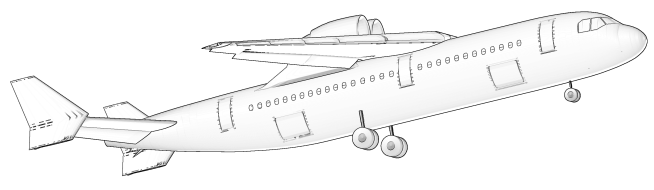

(b) V-2

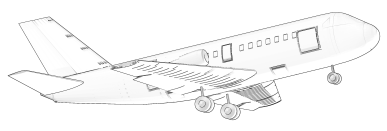

(c) ATTAS

Figure 1: PrADO simulation models of virtual and existing aircraft, see Ref. ${ }^{6}$ and Ref. ${ }^{31}$

aircraft and engine main design parameters. As such, each variant is a valid aircraft model. Each variant was simulated along a defined design mission and along individual approach and departure trajectories to predict performance and system noise. For the 2013 design study, certain key aircraft design parameters were adapted to maximize noise shielding of the engine fan, e.g., parameters such as engine location and wing area were modified. Based on this study, the most promising low-noise aircraft and the conventional reference were selected as input for TC-1, i.e., vehicles V-R and V-2 ${ }^{6}$ as depicted in Figs. 1(a) and 1(b), respectively. Both vehicles are equipped with a conventional turbofan engine (BPR 6) that is described with high-quality engine data from the DLR Institute of Propulsion. Key aircraft performance and design parameters are provided in Table 3, Appendix. It is important to keep in mind, that no additional low-noise airframe measures were applied to the low-noise vehicles. The only low-noise measure investigated in Ref. ${ }^{6}$ is fan noise shielding.

The aircraft model for TC-2 is a redesign of an existing aircraft, the VFW-614 with two Rolls Royce / SNECMA M45H engines as depicted in Fig. 1(c). Such an aircraft was operated as the DLR flying testbed "ATTAS" for many years. The redesign was performed with PrADO and again the engine data is provided from high-fidelity simulation at the DLR Institute of Propulsion. This vehicle has specifically been selected for this comparison because the engines are mounted above the wing hence some noise shielding to the ground can be expected. Numerical predictions for this aircraft based on the flight data recordings can directly be compared to available experimental data that has been provided to NASA and ONERA, see Ref. ${ }^{31}$. Some key aircraft performance and design parameters are provided in Table 3, Appendix. However, prediction of TC-2 was not accomplished during the time of this collaboration. 
Based on the input data provided by DLR, the other two organizations were able to perform their acoustic simulations. Yet, the input data provided correspond to that required to run DLR's PANAM code. Any other input required to run the ANOPP and CARMEN codes are defined by NASA and ONERA, respectively. The assumptions and approximations made were documented and shared with all 3 parties to enable a direct comparison of all test cases. In the following section, each Technical Challenge (TC) is described in more detail, i.e., TC-1 (with assessment of constant flight condition and assessment along typical flight procedures) and TC-2. Thereafter, the available initial results for each test case are presented.

\section{B. Technical Challenge 1-a: Constant flight condition}

Vehicles V-R and V-2 are simulated under constant operating conditions as would be experienced along typical approach and departure flights. In a first step, the noise emission, i.e., spectral shape and directivity, is evaluated (simulation runs 1-4 from Table 2). In a second step, both vehicles are simulated along simplified horizontal flight segments (simulation runs 5-8 from Table 2). These simplified trajectories are straight flight segments under the same constant operating condition from the emission simulation. Predictions along these simplified trajectories can be assembled into time-level histories. The time-level histories are evaluated at two observer locations for departure and approach, respectively. The first observer is directly below the flight track, and the second ground observer is aligned to the aircraft under an azimuthal angle $\Phi$ of $56^{\circ}$, i.e., typical angle associated with the sideline certification location ${ }^{\mathrm{a}}$. For simplicity, only the flyover condition is considered for the V-R vehicle. The V-2 vehicle is also assessed at the sideline observer due to different shielding effects for the flyover and sideline locations.

The results from the simulations performed for test case 1-a will be used to determine the following information:

1. Relative ranking of noise source components for the V-R and V-2 vehicles for 2 constant flight conditions: approach and takeoff.

2. Component and total noise spectra, frequency integrated metrics, frequency-time integrated metrics:

- Installation effects due to the airframe, i.e., scattering effects.

- Emission vs. impact: Results at source observers and ground observers, i.e., changes to source rank-order.

3. Ground noise rank order changes between V-R and V-2.

4. General differences between the methodologies used and the results obtained with the different prediction tools.

\section{Technical Challenge 1-b: Variable condition case}

For this test case, vehicles V-R and V-2 are considered. Both vehicles are simulated along an entire departure and approach procedure with $\operatorname{PrADO}^{6,28}$. For both vehicles, approach and departure procedures are simulated and the system noise is predicted along these flights (simulation runs 9-12, Table 2). The resulting approach and departure

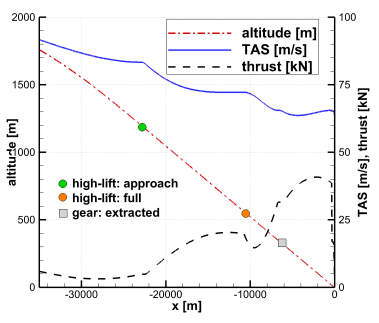

(a) V-R approach

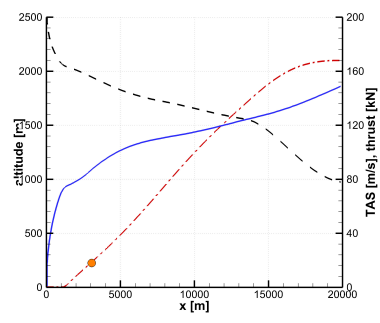

(b) V-R departure

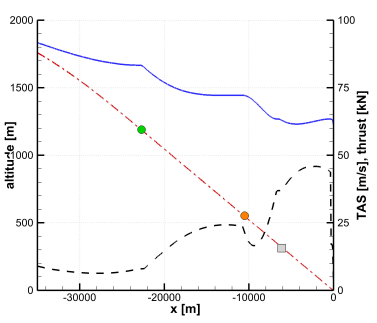

(c) V-2 approach

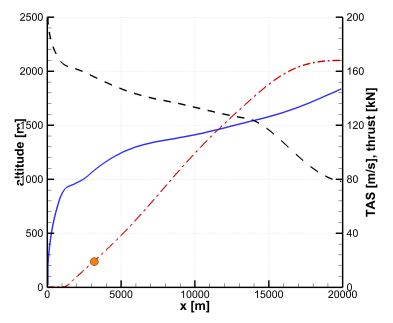

(d) V-2 departure

Figure 2: Simulated flight trajectories for variable condition case (TC 1-b).

trajectories have almost identical altitude profiles but show variations in velocity and thrust profile for V-R and V-2. Obviously, this is due to the differences in flight performance between both aircraft. The flight trajectories are depicted in Figs. 2(a) to 2(d). The defined reference flight procedures do not represent available and practical procedures as

\footnotetext{
${ }^{a}$ Note: Different altitudes of simulated approach and departure flight segments result in different observer locations.
} 
established at major airports, i.e., a simplified and more general definition of the flight procedures was applied ${ }^{\mathrm{b}}$. By selecting similar procedural constraints for the flight simulation of the two aircraft, a comprehensive analysis and fair comparison of the predicted effects is ensured.

The main information to be determined from test case 1-b is as follows:

1. Contour area/shape for each component and overall vehicle.

2. Ground noise impact due to configurational changes.

3. Sensitivity due to component noise variations and ranking.

4. General differences between the methodologies used and the results obtained with the different prediction tools.

\section{Technical Challenge 2: Comparison of simulation and experimental data}

The input data for TC-2 is comprised of a simulation model of the VFW-614 aircraft, i.e., the former flying testbed "ATTAS" of DLR. The model is depicted in Fig. 1(c) and some aircraft specific data is provided in Table 3, Appendix. TC-2 features a detailed comparison of simulated and measured noise data from a previous flight test campaign with "ATTAS" in $2009^{31}$. All flights have been recorded at specific observer locations and data is available for a direct comparison of A-weighted SPL level-time histories for a total of 7 flyover events (simulation runs 13-19, Table 2). Each partner predicts the noise impact according to the provided DLR input data. Finally, all predictions can then be compared to each other and to the measured noise levels.

In general, the following information will be gained from TC-2:

1. Detailed analysis of simulation results: correct representation of the time-level-history for all selected components.

2. Difference between prediction and experiment: time-level-history of prediction versus simulation.

3. Predicted simulation uncertainties versus differences between prediction result and experiment.

4. Differences among the three simulation tools.

${ }^{b}$ Note: The second configurational change along the approach procedures is simulated very slowly hence cannot directly be compared to realistic flight procedures. 


\section{Results}

The benchmark problem has been predicted by all three organizations. Simulation results for TC-1 are available for comparison (simulation runs 1-12, Table 2) whereas simulations of TC-2 are left to possible, future work by the ANSWr group. In this paper, the results of TC-1 for the reference vehicle V-R are presented while the results for V-2 are presented in a companion paper ${ }^{2}$. First, results for simulation runs 1-2 and 5-6 as defined in Table 2 have been generated and are presented in the following sections.

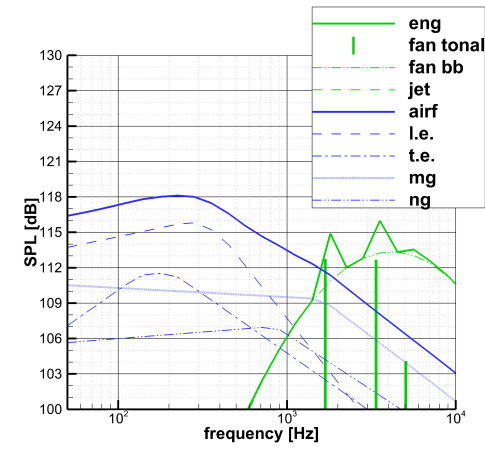

(a) PANAM, $60^{\circ}$

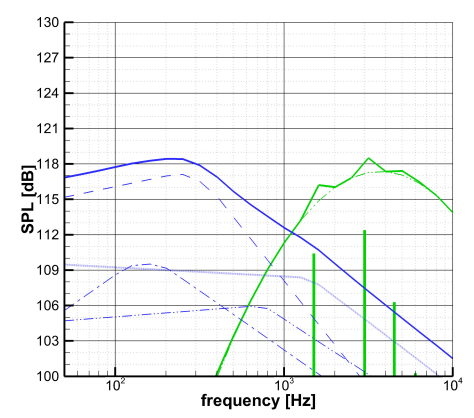

(d) PANAM, $90^{\circ}$

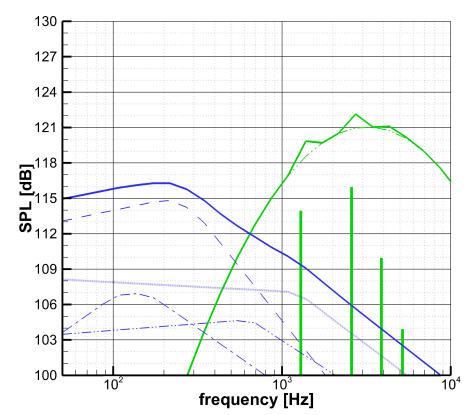

(g) PANAM, $135^{\circ}$

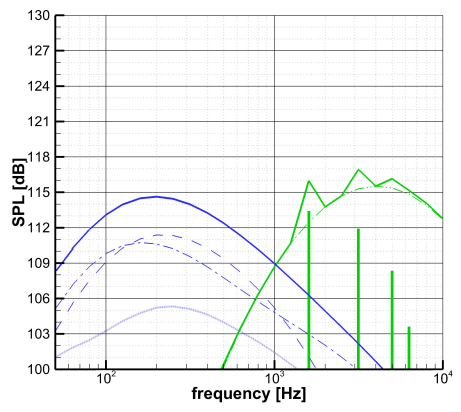

(b) ANOPP, $60^{\circ}$

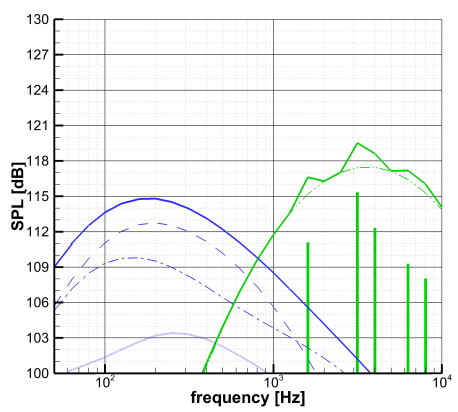

(e) ANOPP, $90^{\circ}$

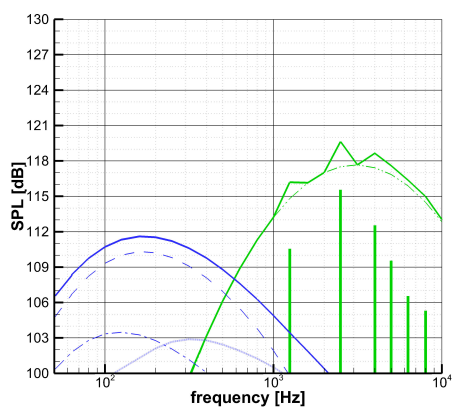

(h) ANOPP, $135^{\circ}$

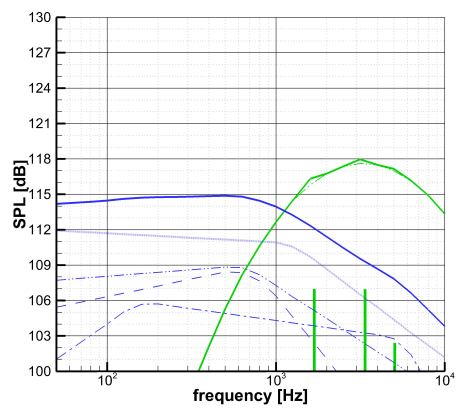

(c) CARMEN, $60^{\circ}$

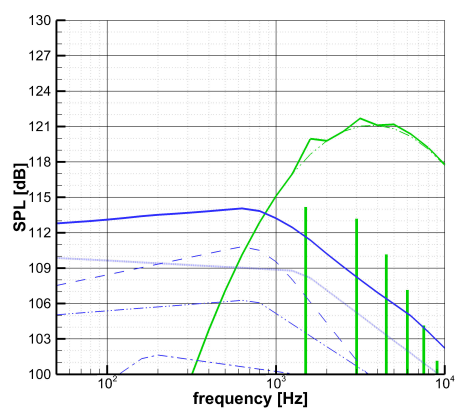

(f) CARMEN, $90^{\circ}$

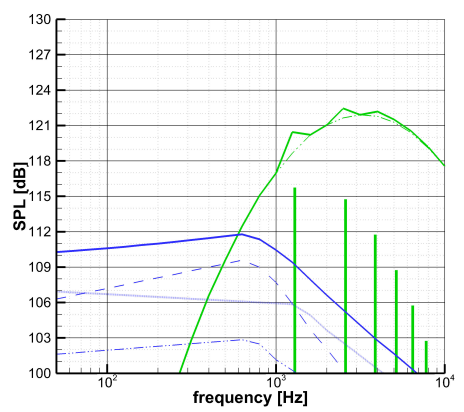

(i) CARMEN, $135^{\circ}$

Figure 3: TC-1a - approach condition: Predicted $60^{\circ}$ (first line), $90^{\circ}$ (second line), and $135^{\circ}$ (third line) emission spectra for PANAM (left column), ANOPP (middle column), and CARMEN (right column).

\section{A. TC-1a}

The predicted source directivities for each simulation tool are assessed for the selected fixed operating condition (simulation runs 1-2, Table 2). Three emission angles are selected for this assessment, i.e. $60^{\circ}, 90^{\circ}$, and $135^{\circ}$. The 
noise source breakdown for the selected airframe and engine noise sources for the three simulation tools is presented side-by-side in Fig. 3 for the approach and Fig. 5 for the departure.

The spectral shapes of the fan noise predicted by all 3 tools are remarkably similar. The frequency of the peak fan noise level is also similarly predicted at just above $3 \mathrm{kHz}$ by all three tools. However, some differences in the amplitude of the spectral peaks and of individual tones in the results obtained with each tool are observed. At each directivity angle, the differences in amplitudes is typically within 3-4 dB.

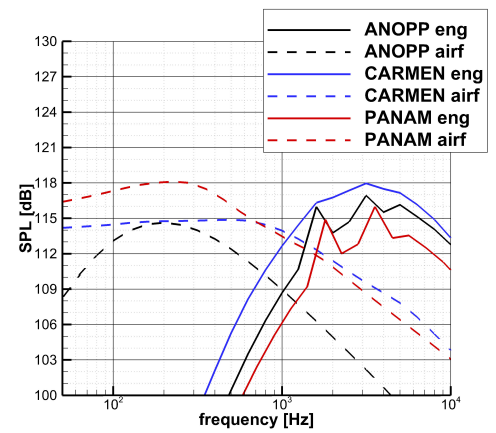

(a) $60^{\circ}$

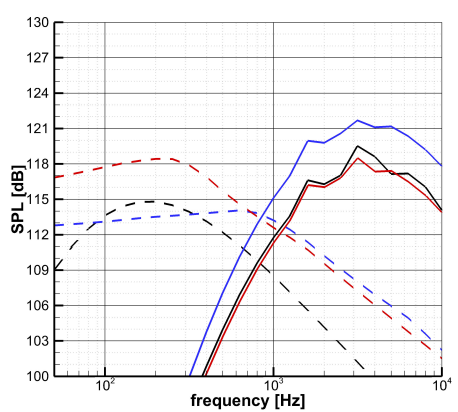

(b) $90^{\circ}$

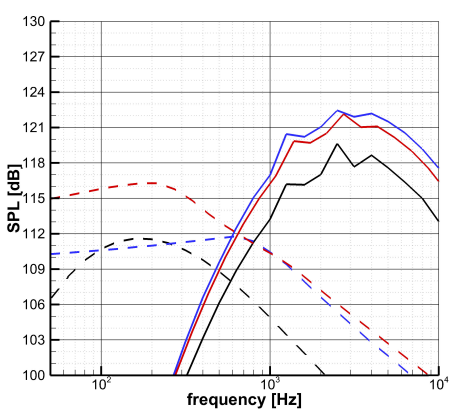

(c) $135^{\circ}$

Figure 4: TC-1a - approach condition: Comparison of overall emission predictions at $60^{\circ}(\mathrm{left}), 90^{\circ}$ (middle), and $135^{\circ}$ (right).

For the prediction of the total airframe noise, all three tools predict spectral peak levels that are within 3-4 dB of each other at all three directivity angles. However, when examining the spectra of individual airframe components, significant differences are evident between the three tools. The spectra from the ANOPP airframe prediction shows a much sharper roll-off both in the high and low frequencies as compared to the total airframe spectra produced from the PANAM and CARMEN predictions (see Fig. 3). The three tools agree that leading edge noise is the dominant airframe component, however, the peak levels can be different by as much as $4 \mathrm{~dB}$ and the peak frequency can be different by several hundred Hz. Similarly, the main gear noise spectral peak levels predicted by each tool can be different by up to $6 \mathrm{~dB}$. There is also a very different prediction of the spectral shape of the main gear noise.

Figure 4 shows the direct comparison of total engine noise and total airframe noise levels at the three polar angles of $60^{\circ}, 90^{\circ}$, and $135^{\circ}$, respectively. The agreement in the predictions obtained with the 3 tools for the total engine noise is clear, as are the differences observed for the predicted total airframe noise.

Similar predictions as in Fig. 3 are shown in Fig. 5 for the departure condition. The fan and jet noise spectra predicted by each tool are presented. The peak frequencies and spectral shapes are in good agreement, while the amplitude of the tones and broadband noise levels can be different by up to 3-4 $\mathrm{dB}$.

Fig. 6 compares the total engine predictions for the three tools at each of the three polar angles. This direct comparison highlights the observations made from Fig. 5.

Next, the predicted time-level histories are discussed (simulation runs 5-6, Table 2). As stated earlier, only a direct flyover situation is considered here, and no sideline observer is assessed. The predicted component time-level history at approach is presented in Figs. 7(a) to 7(c) for each of the three tools. The differences in airframe noise from the three tools is evident with peak levels and the rank order of sources being quite different. The total engine noise is predicted by all three tools to be higher than the total airframe noise and, therefore, dominates the total aircraft time-history in Fig. 8(a) resulting in an agreement, at the peak, within $2 \mathrm{~dB}$ between the three tools.

For the departure, predicted time-level histories are shown in Fig. 7(a) for PANAM, in Fig. 7(b) for ANOPP, and in Fig. 7(c) for CARMEN. The predicted direct comparison for total aircraft noise along the simplified departure is shown in Fig. 8(b). With engine noise dominating at departure and all three tools having shown similar engine levels, Fig. 7 shows this agreement to within 2-3 dB. The transition from inlet noise to aft fan noise is also clearly displayed by all three tools with the double peak in the time history.

\section{B. TC-1b}

The V-R aircraft concept is simulated along the approach trajectory, Figs. 2(a), and the departure trajectory, Figs. 2(b). The resulting system noise is evaluated on a grid of observers in order to generate noise footprints. Predicted SEL 


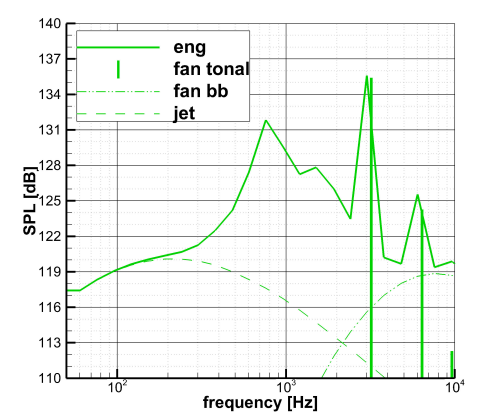

(a) PANAM, $60^{\circ}$

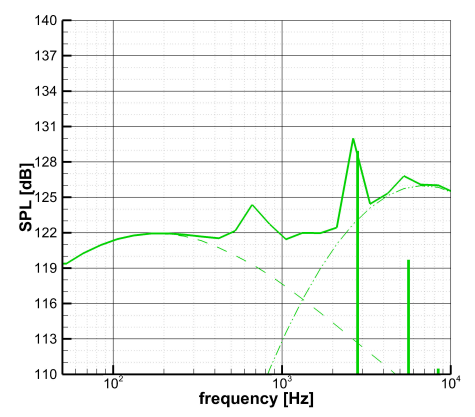

(d) PANAM, $90^{\circ}$

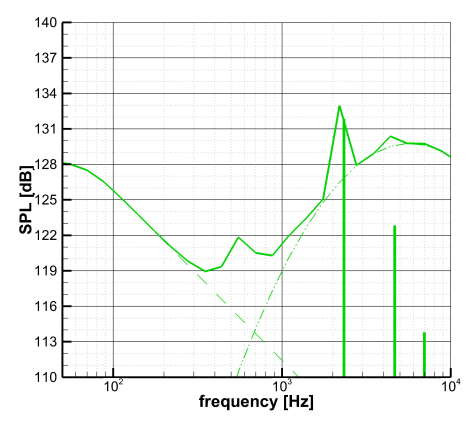

(g) PANAM, $135^{\circ}$

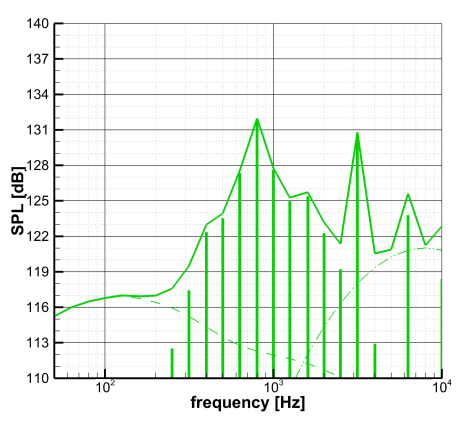

(b) ANOPP, $60^{\circ}$

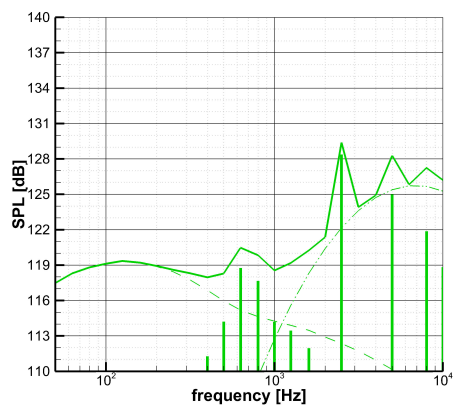

(e) ANOPP, $90^{\circ}$

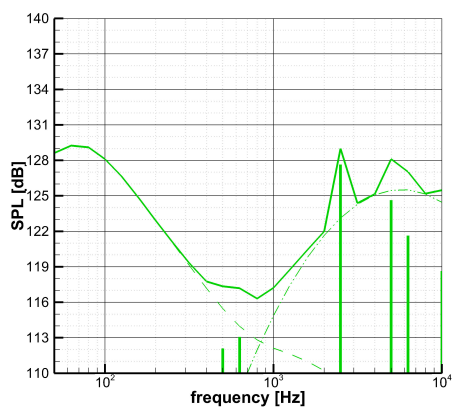

(h) ANOPP, $135^{\circ}$

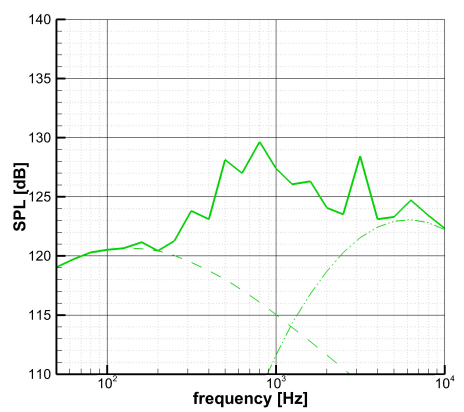

(c) CARMEN, $60^{\circ}$

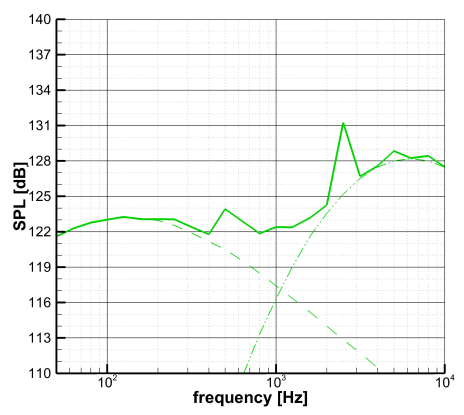

(f) $\mathrm{CARMEN}, 90^{\circ}$

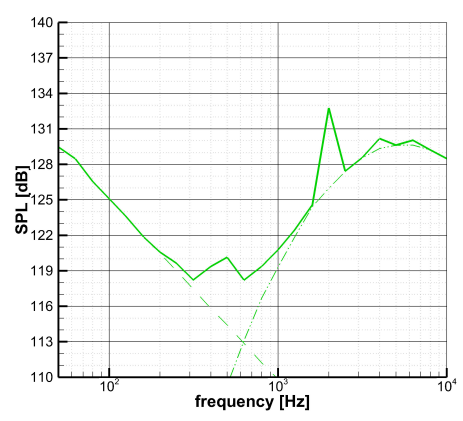

(i) CARMEN, $135^{\circ}$

Figure 5: TC-1a - departure condition: Predicted $60^{\circ}$ (first line), $90^{\circ}$ (second line), and $135^{\circ}$ (third line) emission spectra for PANAM (left column), ANOPP (middle column), and CARMEN (right column). 


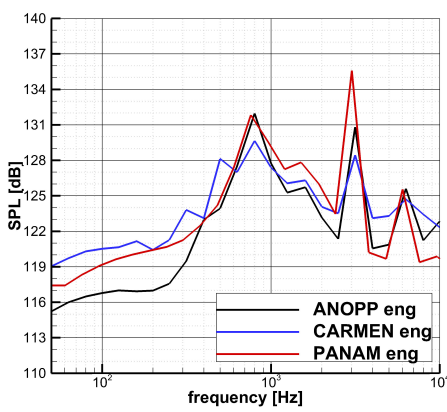

(a) $60^{\circ}$

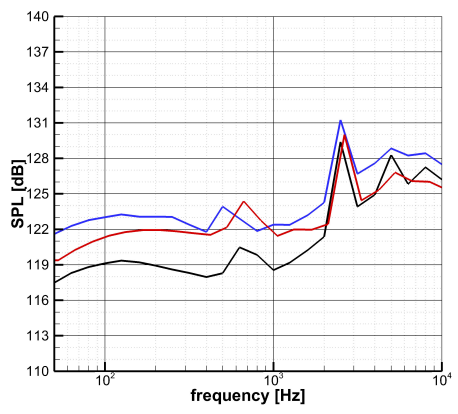

(b) $90^{\circ}$

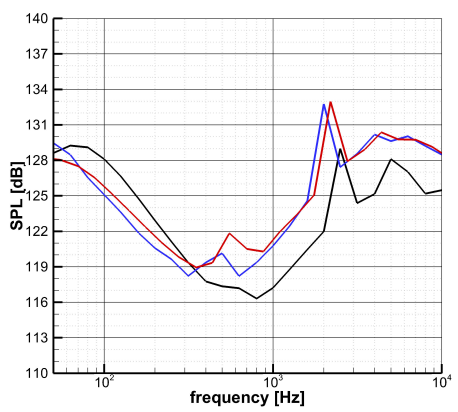

(c) $135^{\circ}$

Figure 6: TC-1a - departure condition: Comparison of overall emission predictions at $60^{\circ}$ (left), $90^{\circ}$ (middle), and $135^{\circ}$ (right).

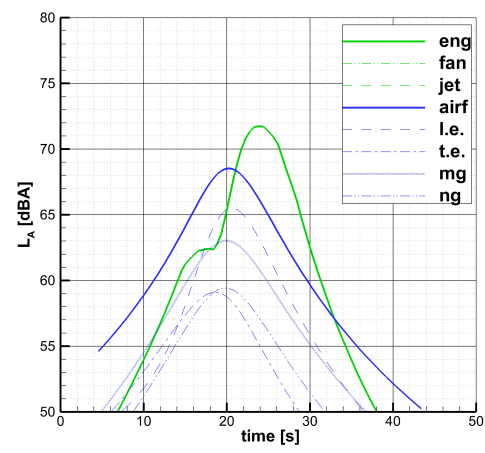

(a) PANAM approach

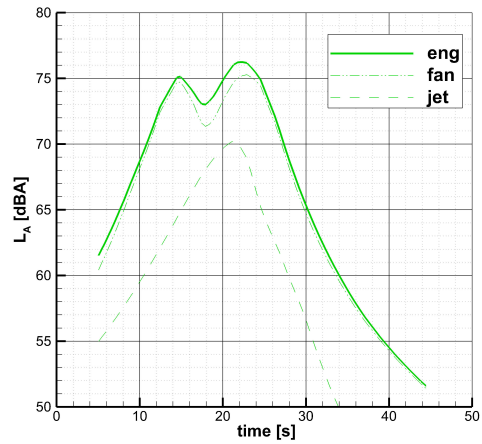

(d) PANAM departure

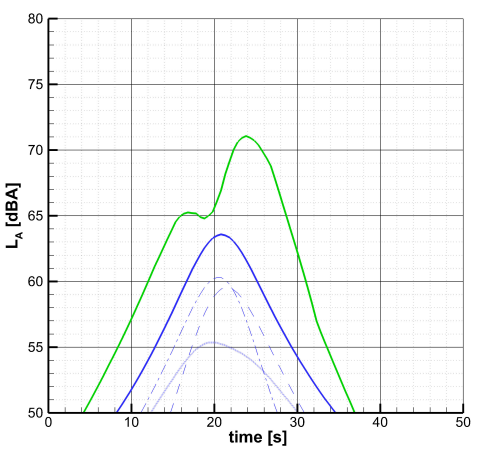

(b) ANOPP approach

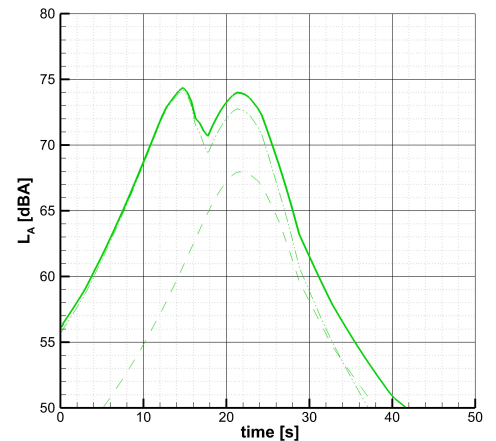

(e) ANOPP departure

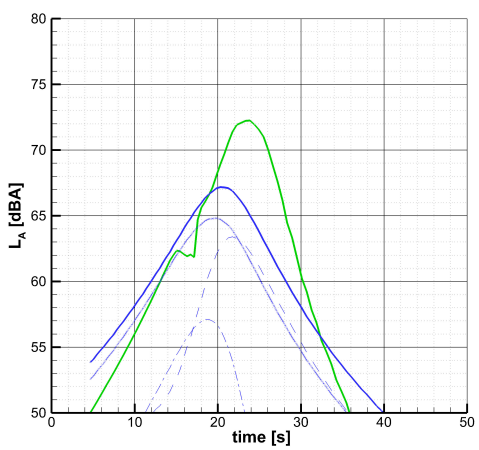

(c) CARMEN approach

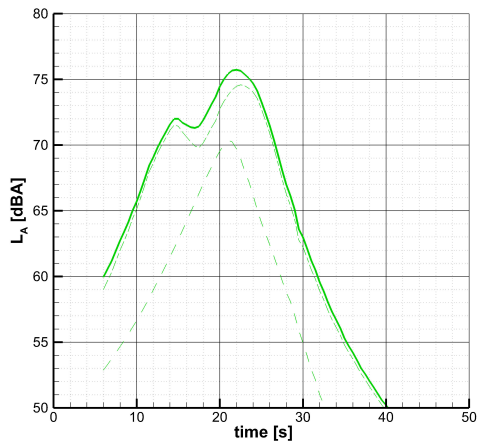

(f) CARMEN departure

Figure 7: TC-1a - simplified approach (top) and departure (bottom): Componential time-level history. 


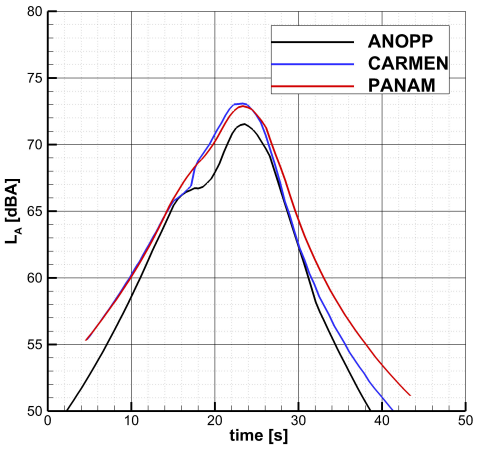

(a) comparison approach

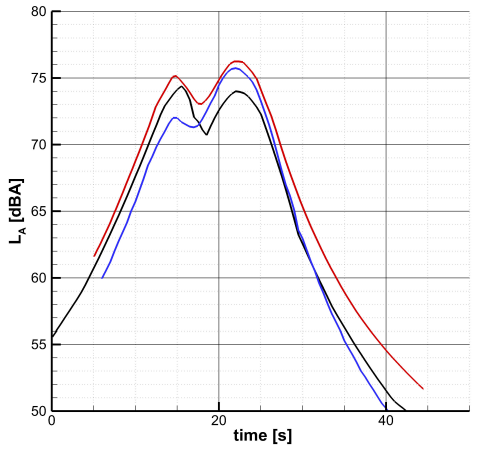

(b) comparison departure

Figure 8: TC-1a - simplified approach (left) and departure (right): Direct comparison of total aircraft noise prediction.

footprints are presented for each simulation tool for the approach isocontour areas in Fig. 9(a) PANAM, Fig. 9(b) ANOPP, and Fig. 9(c) CARMEN. In general, the agreement is very good both in terms of overall characteristics of the ground contours. Differences increase at distances far away from touchdown in lower levels of isocontours. These differences are quantified in Fig. 9(d).

Similarly, for the departure trajectory, the predictions of all three tools are shown in Fig. 10 with the differences in the tools compared in Fig. 10(d). Again, overall there is good agreement.

\section{Conclusions}

Initiated by DLR and together with ONERA and NASA, the Aircraft Noise Simulation Working Group, ANSWr, was formed to investigate simulations of the same well defined aircraft concepts. Defined by DLR, the V-R aircraft concept is a conventional technology aircraft type with engines mounted under the wings. The engine, airframe, and trajectories were all provided by $\mathrm{DLR}^{6,28-31}$ and then predicted by all three organizations.

The presented Technical Challenges (TC) have been selected in order to answer certain research questions as listed in Section B. By working on the TCs, general similarities and differences in approaches and results were identified.

All three tools are time step models, i.e., the aircraft trajectory is defined as a series of flight points. An emission prediction for each of these flight steps is performed by applying parametric noise source models while accounting for effects of varying operational and geometrical input parameters on the predicted noise emission. Various simulation models are available at each organization and certain noise source models were selected and applied within PANAM, ANOPP, and CARMEN, respectively. The emission prediction is then followed by a sound propagation simulation through the atmosphere where all three tools use simplified propagation models. In conclusion, the setup of the simulation tools is in general very similar with remaining differences in the individual code implementation. According to Ref. ${ }^{32}$ all three tools can be classified as scientific tools compared to the best practice tools, e.g., FAA's Aviation Environmental Design Tool. During planing and performing the benchmark test, knowledge and experience in the area of aircraft system noise prediction was shared among the organizations.

To compare the simulation results, certain guidelines have been defined and three test cases are assessed. First, the noise emission is evaluated for predefined and constant operating conditions as might be experienced during typical approaches and departures. Here, the unweighted third-octave band spectra are compared for each noise source including moving source effects. Second, the noise immission is assessed along two simplified flyover situations under consideration of sound propagation effects at a predefined observer location. Third, the SEL isocontours are compared along an entire approach and departure flight.

For the V-R concept, all three prediction methods show good agreement, typically within 3-4 dB, for overall aircraft noise metrics such as peak noise level and also for the overall characteristics of ground isocontours. It is important to note that while the V-R concept is well defined, it is specifically simplified for this benchmark test compared to realistic aircraft, which furthermore include effects such as reflection, duct lining attenuation, core noise, and other effects.

The prediction of fan noise particularly compares well across the three codes in terms of spectral shape and peak frequencies, although peak levels can be different by 3-4 dB. In addition, jet noise also generally compares well. This 
agreement is attributed to a common framework in the formulation of the methods.

In contrast, the prediction of airframe noise by the three tools shows considerable differences in source rank order, directivity, and spectral shape. Some differences can be $6 \mathrm{~dB}$ or more for the major airframe components between the three tools. Less discrepancies are found between CARMEN and PANAM because for certain noise sources, similar airframe source models have been applied. However, after the sources are summed to the total airframe noise level, the differences are minimized somewhat to be about 3-4 dB. The fundamental differences between the airframe methods is likely the result of completely different approaches to modeling the airframe sources as well as basis on different aircraft design types.

Two of the main ANSWr goals as specified in Section B have not been addressed in this paper: (1) identification of uncertainties associated with individual simulation capabilities and (2) identification of challenges and needed modeling improvements for novel technologies and unconventional aircraft designs. The assessment of uncertainties is still under investigation at the three research organizations and is therefore not addressed here. Initial work on uncertainty assessment at DLR and NASA is documented in Refs. ${ }^{33}$ and $^{34}$. Noise shielding effects which are of utmost importance for novel low-noise configurations are addressed in the accompanying paper $^{2}$ where prediction results for the V-2 aircraft are described and discussed.

\section{Acknowledgments}

The funding for the DLR work package was partially supported by the DLR Projekfoerderung zur Internationalen Zusammenarbeit and the DLR Directorate Aeronautics. The NASA contribution to the ANSWr collaboration is funded by the Aircraft Noise Reduction Subproject of the Advanced Air Transport Technology Project. The ONERA contribution to the ANSWr collaboration is funded by internal budget dedicated to international collaborations. Furthermore, the authors would like to thank Mrs. Casey Burley for her valuable contribution to initiate and setup the ANSWr benchmark test.

\section{References}

\footnotetext{
${ }^{1}$ International Civil Aviation Organization (ICAO): Guidance on the Balanced Approach to Aircraft Noise Management. ICAO Doc.9829, 2nd edition, 2008.

${ }^{2}$ L. Sanders, R.H. Thomas, L. Bertsch et al.: The Aircraft Noise Simulation Working Group (ANSWr) - V-2 Aircraft Results, AIAA Aeroacoustics Conference 2019, Delft, Netherlands

${ }^{3}$ R. Schmid: Half-empirical, physical model for the directional characteristic of sound radiated by modern turbofan engines, Doctoral Thesis University of Goettingen, Germany, DLR-Forschungsbericht 1999-47, ISSN 1434-8454, 2000

${ }^{4}$ W. Dobrzynski, L. Chow, P. Guion, D. Shiells: A European Study on Landing Gear Airframe Noise Sources, 6th AIAA/CEAS Aeroacoustics Conference, 12-14 June 2000, Lahaina Hawaii/USA

${ }^{5}$ W. Dobrzynski, M. Pott-Pollenske: Slat Noise Source Studies for Farfield Noise Prediction, AIAA-2001-2158, 7th AIAA/CEAS Aeroacoustics Conference, 28 - 30 May 2001, Maastricht, Netherlands

${ }^{6}$ L. Bertsch: Noise Prediction within Conceptual Aircraft Design, DLR Forschungsbericht, ISRN DLR-FB-2013-20, 2013

${ }^{7}$ W.E. Zorumski: Aircraft Noise Prediction Program Theoretical Manual, NASA TM-83199, 1982

${ }^{8}$ V. Lopes, C. L. Burley: Design of the Next Generation Aircraft Noise Prediction Program: ANOPP2, 17th AIAA/CEAS Aeroacoustics Conference (32nd AIAA Aeroacoustics Conference), Portland, Oregon, 5-8 June, 2011

${ }^{9}$ R. Thomas, C.L. Burley, E.D. Olson: Hybrid wing body aircraft system noise assessment with propulsion airframe aeroacoustic experiments, International Journal of Aeroacoustics, Volume 11, number 3+4, 2012

${ }^{10}$ R. Thomas, C.L. Burley, C.L. Nickol: Assessment of the Noise Reduction Potential of Advanced Subsonic Transport Concepts for NASA's Environmentally Responsible Aviation Project, 54th AIAA Aerospace Sciences Meeting, AIAA SciTech Forum, AIAA 2016-0863

${ }^{11}$ M. Brunet, P. Malbequi, W. Ghedhaifi: A novel approach to air transport system environmental impact evaluation through physical modelling and simulation, 26th International Congress of the Aeronautical Sciences (2008)

${ }^{12}$ Rosenberg, Bulté: Fast Aircraft Noise Prediction Including Installation Effects for the Evaluation of Air Transport Systems, Internoise, 2008

${ }^{13}$ P. Malbéqui, Y. Rozenberg, J. Bulté: Aircraft noise modelling and assessment in the IESTA program, Internoise 2011

${ }^{14}$ C. Burley, J.W. Rawls, J.J. Berton, M.A. Marcolini: Assessment of NASA's Aircraft Noise Prediction Capabilities - Chapter 2: Aircraft System Noise Prediction, NASA Technical report, NASA/TP-2012-215653, 2012

${ }^{15}$ V. Fleury, P. Malbéqui: Slat Noise Assessment from Airbus A340 Flyover Phased-Array Microphone Measurements, AIAA Journal, Vol. 51, No. 7, 2013
} 
${ }^{16}$ M. Pott-Pollenske, W. Dobrzynski, H. Buchholz, B. Gehlhar, F. Walle: Validation of Semiempirical Airframe Noise prediction Method through Dedicated A319 Flyover Noise Measurements, AIAA paper 2002-2470, 8th AIAA/CEAS Aeroacoustics Conference \& Exhibit, Breckenridge, Colorado, 2002

${ }^{17}$ K.-S. Rossignol: Development of an empirical prediction model for flap side-edge noise, AIAA-2010-3836, 16th AIAA/CEAS Aeroacoustics Conference, 7 - 9 June 2010, Stockholm, Sweden

${ }^{18}$ K.-S. Rossignol: Empirical Prediction of Airfoil Tip Noise, AIAA-2011-273, 17th AIAA/CEAS Aeroacoustics Conference, 6-8 June 2011, Portland, Oregon, USA

${ }^{19}$ Y. Guo: Flap Side Edge Noise Prediction Model, NASA Contract NNL07AA03A, The Boeing Company, Huntington Beach, CA, July 2009

${ }^{20}$ M.R. Fink: Airframe Noise Prediction Method, FAA Research Report, FAA-RD-77-29, March 1977

${ }^{21}$ Y. Guo: Aircraft Slat Noise Modeling and Prediction, AIAA 2010-3837

${ }^{22}$ Y. Guo: An Improved Landing Gear Noise Prediction Scheme, NASA/CR NAS1-NNL04AA11B Task NNL06AB63T, The Boeing Company, Huntington Beach, CA, November 2006

${ }^{23}$ M.F. Heidmann: Interim prediction method for fan and compressor source noise, NASA Technical Report TM-X-71763, 1979

${ }^{24}$ K. Kontos, B. Janardan, P. Gliebe: Improved NASA-ANOPP Prediction Computer Code for Advanced Subsonic Propulsion Systems, NASA CR-195480, 1996

${ }^{25}$ J.R. Stone, D.E. Groesbeck, C.L. Zola: Conventional profile coaxial jet noise prediction, AIAA Journal, 21(1) (1983), pp. 336-342

${ }^{26}$ J.R.Stone, E.A. Krejsa, B.J.Clark: Jet Noise Modelling for Suppressed and Unsuppressed Aircraft in Simulated Flight, NASA/TM 2009-215524, 2009

${ }^{27}$ International Organization for Standardization, Acoustics - Attenuation of sound during propagation outdoors - Part 1: Calculation of the absorption of sound by the atmosphere, ISO 9613-1:1993, 1993

${ }^{28}$ W. Heinze: Beitrag zur quantitativen Analyse der technischen und wirtschaftlichen Auslegungsgrenzen verschiedener Flugzeugkonzepte für den Transport grosser Nutzlasten, ZLR-Forschungsbericht 94-01, ISBN 3-928628-14-3

${ }^{29}$ F. Deidewig: Ermittlung der Schadstoffemissionen im Unter- und Ueberschallflug, German Aerospace Center, DLR Forschungsbericht 98-10, Collogne, Germany, 1998 (in German)

${ }^{30}$ L. Bertsch, W. Heinze, M. Lummer: Application of an Aircraft Design-To-Noise Simulation Process, 14th AIAA Aviation Technology, Integration, and Operations Conference, DOI: 10.2514/6.2014-2169, Atlanta, USA, 2014

${ }^{31}$ L. Bertsch, G. Looye, E. Anton, S. Schwanke: Flyover Noise Measurements of a Spiraling Noise Abatement Approach Procedure, Journal of Aircraft, 48 (2), pages 436-448, DOI: 10.2514/1.C001005, March - April 2011

${ }^{32}$ U. Isermann, L. Bertsch: Aircraft Noise Immission Modeling, In: CEAS Aeronautical Journal Special Issue: Aircraft Noise

${ }^{33}$ J. June, R. H. Thomas, and Y. Guo: Aircraft System Noise Prediction Uncertainty Quantification for a Hybrid Wing Body Subsonic Transport Concept, 2018 AIAA/CEAS Aeroacoustics Conference, AIAA AVIATION Forum, (AIAA 2018-3125), DOI: 10.2514/6.2018-3125

${ }^{34}$ L. Bertsch, B. Schäffer, S. Guérin: Uncertainty analysis for parametric aircraft system noise prediction, AIAA Journal of Aircraft, 2018, DOI: 10.2514/1.C034809 Generation and Assessment, 2019, DOI: 10.1007/s13272-019-00374-5 


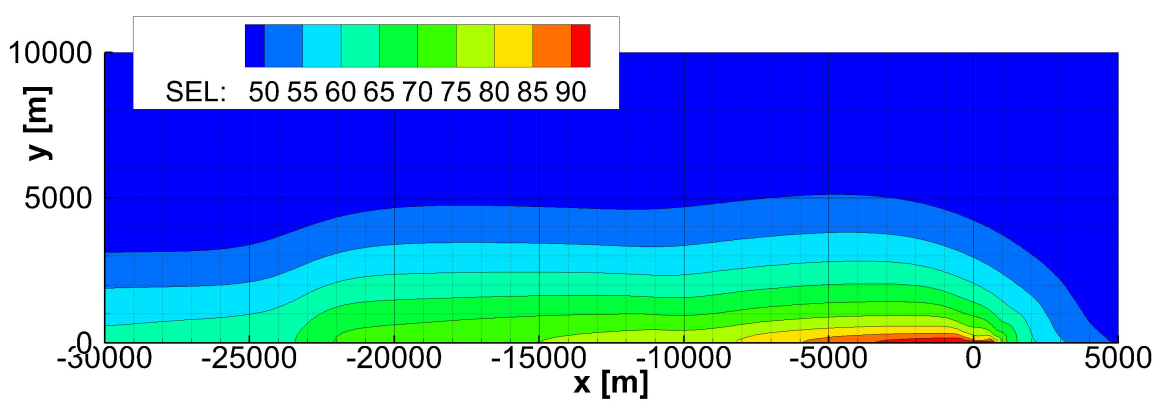

(a) PANAM

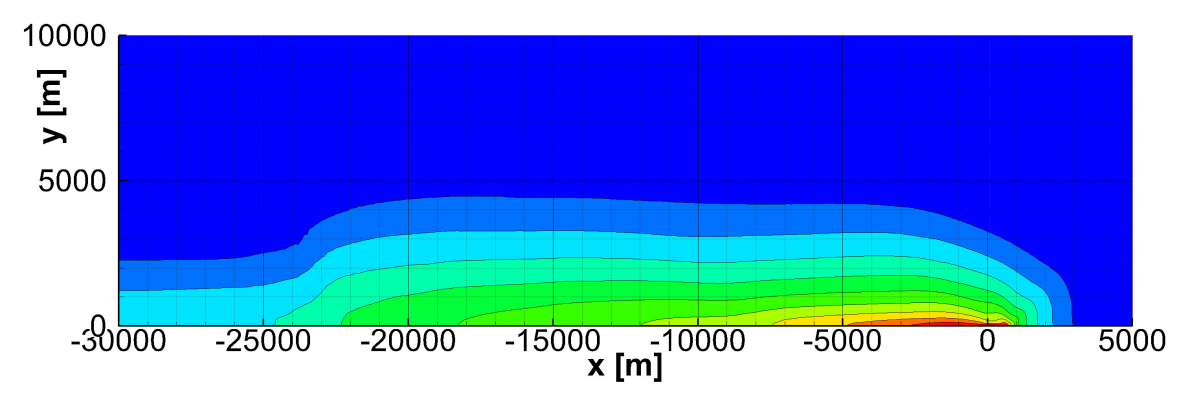

(b) ANOPP

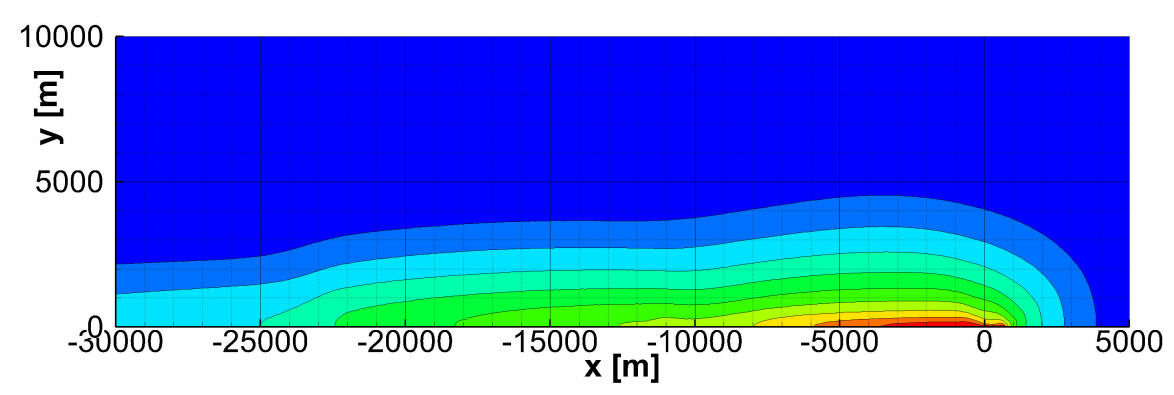

(c) CARMEN

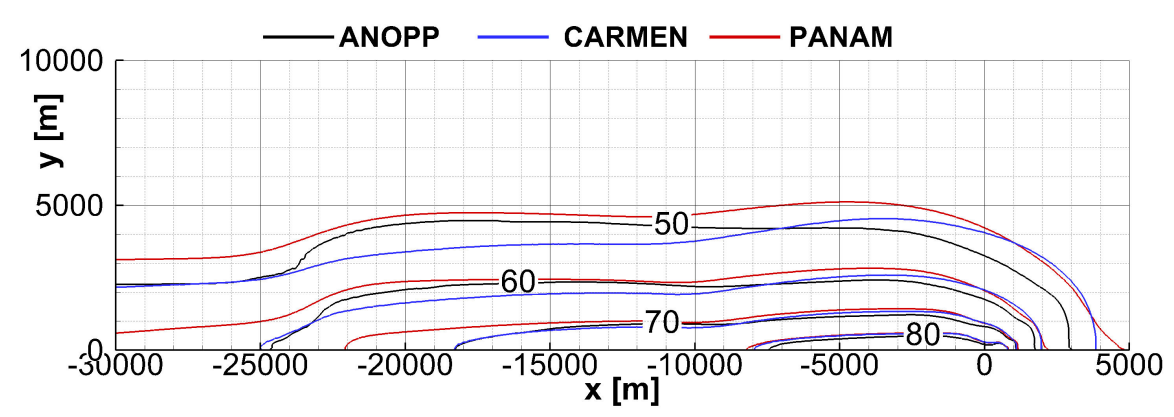

(d) comparison

Figure 9: TC-1b - approach: Predicted SEL footprints and direct comparison of isocontour areas. 


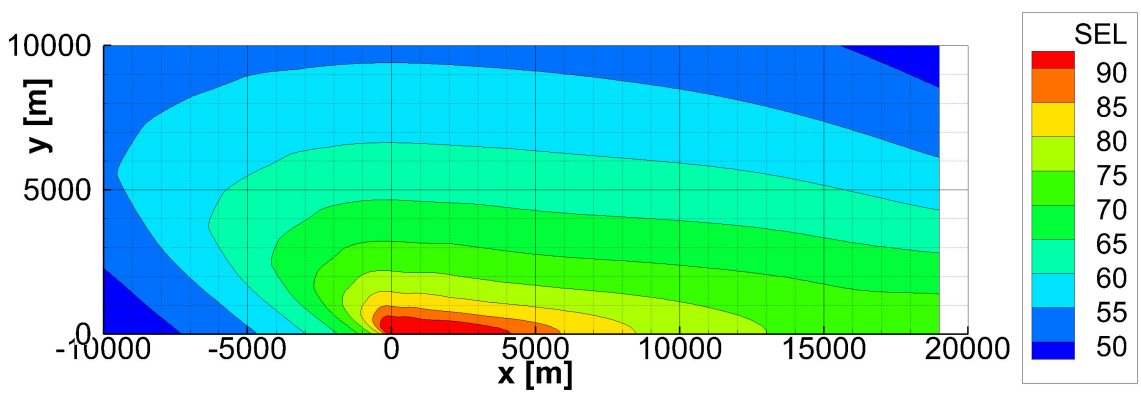

(a) PANAM

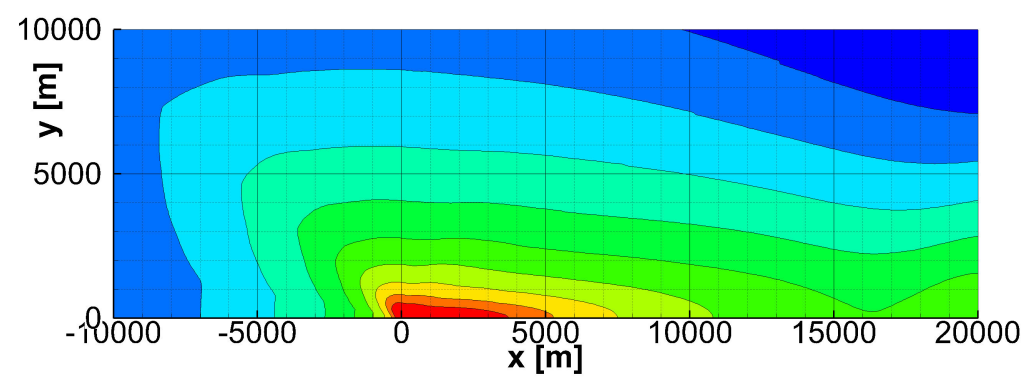

(b) ANOPP

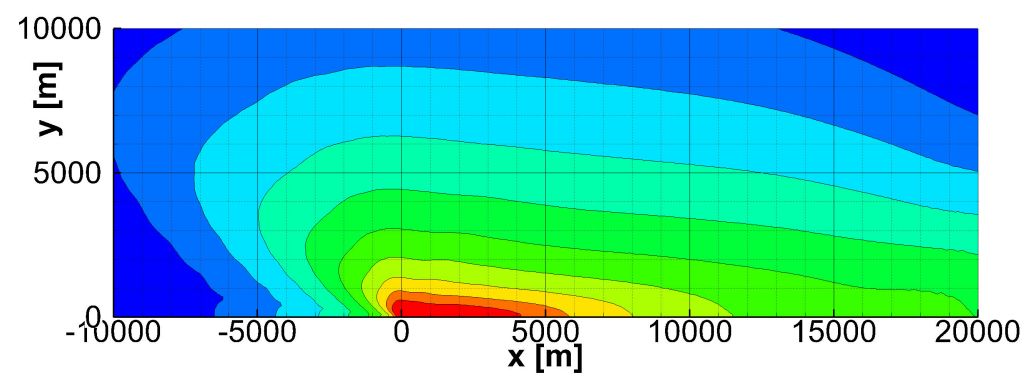

(c) CARMEN

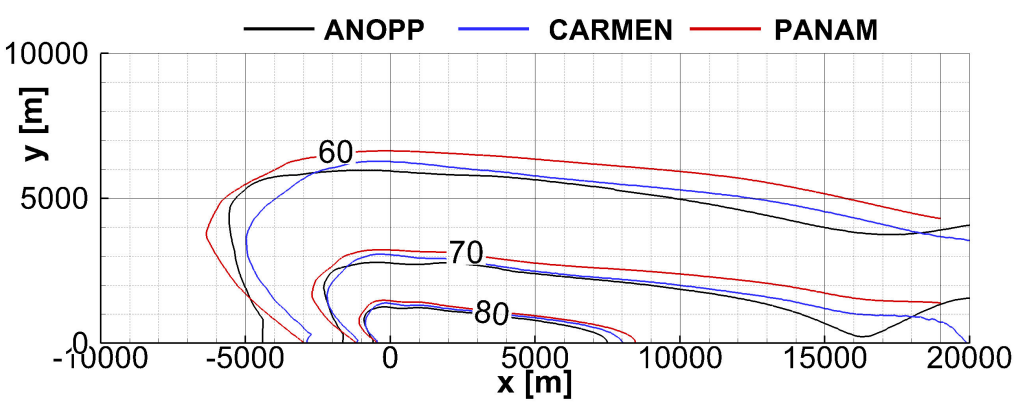

(d) comparison

Figure 10: TC-1b - departure: Predicted SEL footprints and direct comparison of isocontour areas. 


\section{Appendix}

\begin{tabular}{|c|c|c|c|c|}
\hline \# & vehicle & type & output & simplifications \\
\hline \multicolumn{5}{|c|}{ TC-1a: constant flight condition } \\
\hline 1 & V-R & app. & 3 emission spectra & no shielding, no lining, no ground attenuation \\
\hline 2 & V-R & dep. & 3 emission spectra & no shielding, no lining, no ground attenuation \\
\hline $3^{*}$ & $\mathrm{~V}-2$ & app. & 3 emission spectra & no lining, no ground attenuation \\
\hline $4 *$ & $\mathrm{~V}-2$ & dep. & 3 emission spectra & no lining, no ground attenuation \\
\hline \multicolumn{5}{|c|}{ TC-1a: simplified flyover } \\
\hline 5 & V-R & app. & tlh and integrated sound metrics ( 1 obs.) & no shielding, no reflection, no lining, no ground attenuation \\
\hline 6 & V-R & dep. & tlh and integrated sound metrics ( 1 obs.) & no shielding, no reflection, no lining, no ground attenuation \\
\hline $7 *$ & $\mathrm{~V}-2$ & app. & tlh and integrated sound metrics ( 2 obs.) & no lining, no ground attenuation \\
\hline $8^{*}$ & $\mathrm{~V}-2$ & dep. & tlh and integrated sound metrics ( 2 obs.) & no lining, no ground attenuation \\
\hline \multicolumn{5}{|c|}{ TC-1b: simulated flight } \\
\hline 9 & V-R & app. & contour plot (SEL) & no shielding, no reflection, no lining, no ground attenuation \\
\hline 10 & V-R & dep. & contour plot (SEL) & no shielding, no reflection, no lining, no ground attenuation \\
\hline $11^{*}$ & $\mathrm{~V}-2$ & app. & contour plot (SEL) & no lining, no ground attenuation \\
\hline $12 *$ & $\mathrm{~V}-2$ & dep. & contour plot (SEL) & no lining, no ground attenuation \\
\hline \multicolumn{5}{|c|}{ TC-2: measured test flights } \\
\hline $13^{* * *}$ & ATTAS & ILS app. 1 & tlh and integrated sound metrics (6 obs.) & none \\
\hline $14 * *$ & ATTAS & steep app. 1 & th and integrated sound metrics ( 6 obs.) & none \\
\hline $15^{* * *}$ & ATTAS & steep app. 2 & tlh and integrated sound metrics ( 6 obs.) & none \\
\hline $16^{* *}$ & ATTAS & HeNAP 1 & th and integrated sound metrics (12 obs.) & none \\
\hline $17 * *$ & ATTAS & HeNAP 2 & th and integrated sound metrics (12) obs.) & none \\
\hline $18^{* *}$ & ATTAS & HeNAP 3 & th and integrated sound metrics (12 obs.) & none \\
\hline $19^{* *}$ & ATTAS & ILS app. 2 & tlh and integrated sound metrics ( 6 obs.) & none \\
\hline
\end{tabular}

Table 2: Simulation runs for benchmark test (* results presented in accompanying paper $^{2}$, ** future work).

\begin{tabular}{|c|c|c|c|}
\hline & V-R & V-2 & ATTAS \\
\hline \multicolumn{4}{|l|}{ Engine selection } \\
\hline engine & CFM56 & CFM56 & $\mathrm{M} 45 \mathrm{H}$ \\
\hline static thrust $[k N]$ & 104.0 & 104.0 & 32.4 \\
\hline bypass ratio $[-]$ & 5.8 & 5.8 & 2.85 \\
\hline \multicolumn{4}{|c|}{ Top Level Aircraft Requirements (TLAR) } \\
\hline range $[\mathrm{km}]$ & 3334 & 3334 & 416 \\
\hline passengers [-] & 124 & 124 & 44 \\
\hline add. freight $[\mathrm{kg}]$ & 0 & 0 & 0 \\
\hline cruise Mach [-] & 0.76 & 0.76 & 0.61 \\
\hline \multicolumn{4}{|l|}{ Weights } \\
\hline oew $[k g]$ & 38641 & 38005 & 12325 \\
\hline max. take-off $[k g]$ & 60815 & 60541 & 18002 \\
\hline max. landing $[k g]$ & 58588 & 58158 & 18002 \\
\hline \multicolumn{4}{|l|}{ Wing } \\
\hline span width $[m]$ & 33.9 & 31.6 & 21.5 \\
\hline ref. area $\left[\mathrm{m}^{2}\right]$ & 122.6 & 125.0 & 67.4 \\
\hline aspect ratio [-] & 9.4 & 8.0 & 6.86 \\
\hline t/4 sweep a. $\left[{ }^{\circ}\right]$ & 24.0 & 23.3 & 15.0 \\
\hline \multicolumn{4}{|l|}{ Vertical tailplane } \\
\hline span width $[m]$ & 5.87 & $2 * 4.24$ & 3.5 \\
\hline ref. area $\left[\mathrm{m}^{2}\right]$ & 21.5 & $2 * 12.3$ & 9.45 \\
\hline \multicolumn{4}{|l|}{ Horizontal tailplane } \\
\hline span width $[m]$ & 11.8 & 12.3 & 9.0 \\
\hline ref. area $\left[\mathrm{m}^{2}\right]$ & 28.0 & 30.0 & 18.0 \\
\hline \multicolumn{4}{|c|}{ Performance along design mission } \\
\hline flight speed $[\mathrm{km} / \mathrm{h}]$ & 813 & 813 & 685 \\
\hline block time $[h]$ & 4.31 & 4.31 & 0.69 \\
\hline max. field length $[\mathrm{m}]$ & 1909 & 1748 & 1080 \\
\hline fuel req. $[k g]$ & 10179 & 10541 & 1673 \\
\hline
\end{tabular}

Table 3: PrADO simulation results: aircraft design and performance parameters, see Ref. ${ }^{31}$ and Ref. ${ }^{6}$ 